\title{
Objective Function Development Based on the Parameters of a Regional Terminal Network
}

\author{
Valery M. Samuylov, Oksana D. Pokrovskaya, Lyudmila V. Gashkova, Herbert Sonntag*
}

\section{Abstract}

The article is devoted to the development of the objective function for calculating the parameters of a terminal network in a region. The key parameters of a terminal network, as logistic system, are described. The factors influencing the parameters of a terminal network are analyzed, and the objective function, concerning the value and qualitative aspects for determining the transport and spatial/quantitative parameters proposed. The level of service quality for the clients is also taken into account. The heuristic solution method, and the results of the approach are demonstrated with the help of an application example concerning different combinations of distribution

\section{Zusammenfassung}

Der Artikel widmet sich der Modellierung eines Transportnetzes, das, unter Beachtung der Lage der Distributionszentren und der Lage der Kunden, minimale Gesamtlogistikkosten ergibt. Diese setzen sich wiederum aus den Transport- und aus den Standortkosten hinsichtlich der Lager- und Betriebskosten der Distributionszentren zusammen. Darüber hinaus wird auch die Maximierung beziehungsweise das Niveau der Servicequalität für die Kunden einbezogen. Das heuristische Lösungsverfahren wird anschließend an einem Anwendungsbeispiel hinsichtlich unterschiedlicher Kombinationen von Distributionszentren erprobt und hinsichtlich der Zielerreichung dokumentiert.

\section{Introduction}

The idea of forming a terminal network, or a network of logistics consolidating distribution centers (hereafter named LCDCs), means building interconnected and continuous chains of centers. A terminal network in a region is a set of interacting and centrally managed terminals (LCDCs) providing interregional integration and access to the transport corridors of the country. A network of LCDCs is a system of geographically separate sites, which are technologically interconnected through the functions of freight handling: collection, batching and sorting down, transshipment, cross-docking and the delivery of goods to the customers. A terminal network is required to ensure an effective intra-regional distribution, a well-organized freight flow management, as well as the ability of terminal infrastructure to support flows for market entrance.

LCDCs combine shipping, storage and sales functions with providing com- prehensive solutions and a complete set of value-added services for the customers. Within the terminal operation, the delivery of goods to the customers is organized through LCDC networks, where the cargo is stocked, handled and serviced (Pokrovskaya et al. 2013, Samuylov et al. 2012). The purpose of this article is to consider the basic parameters of a terminal network and to develop the objective function for a network parameterization in quantitative and qualitative aspects.

\section{Solution Model Approach}

Spatial/quantitative parameters of the terminal network involve the amount and location of terminal network nodes - LCDCs (terminals) and their proximity to manufacturing facilities. Transport parameters of a terminal network include: the mode of transport (road/rail, selected by each transport combination), the type of delivery (mono-modal or multi-modal) and the type of shipping (direct or terminal). These parameters are affected by the density of industrial/transport nodes, the number and location of customers, the intensity of transport communication and economic ties, the transport and storage infrastructure, the volume and direction of freight flows and the exits to transport corridors, etc.

In addition to these indicators, the organization of a terminal network is influenced by such factors as: socio-demography (population number, cost of living), administration (economy and transport development in the region), economy (competitiveness, amount of investments), industrial potential (industrial output), trading capacity (volume of trade, the availability of logistics and distribution companies), transport (availability and development of transport communications, major carriers) and geography (location of industrial, transport and population centers, ecology).

In accordance with the above-mentioned parameters of a terminal net- 
work, the objective function can be constructed. The algorithm of selecting a rational number and placement of a LCDC is based on the choice of the most profitable alternative from a variety of options. Minimum total costs for transportation service $\left(S_{\text {sum }}\right)$ are considered to be the optimum criterion (Pokrovskaya 2012).

\section{(1) $F=\sum_{1} \sum_{1} \sum_{k}\left[S_{s u m}^{(\beta, \lambda, \beta+\beta)}{ }_{\alpha}\right] \Rightarrow \min$}

Limitations: 1) Sufficient volume of traffic; 2) $S_{\text {trans }} \geq S_{\text {build }}$

Expanded form of the objective function:

$$
\text { (2) } F=\sum_{i} \sum_{i} \sum_{k}\left\lfloor S_{\text {trans }}, S_{\text {butd }}, T_{\text {delivery }}\right\rfloor \Rightarrow \min
$$

where $S_{\text {sum }}(\beta ; \lambda ; \beta+\lambda)$ is the total cost for transportation service, rub./year. $S_{\text {sun }}$ $(\beta ; \lambda ; \beta+\lambda)$ consists of: $S_{\text {trans }}$ - the cost of shipping, rub./ year; $S_{\text {build }}$ - the cost of building the required number of LCDCs, considering investment in infrastructure and handling of freight at warehouses, rub./ year; $T_{\text {delivery }}$-time of delivery using terminal technology, hour.

Expanded form of the cost of shipping function:

$$
\text { (3) } \begin{aligned}
F\left(S_{\text {traus }}\right) & =\left(\sum_{i} \sum_{k} Q_{i k} S_{\text {trans }(i k)}+\sum_{m} Q_{i k} S_{\text {traus }(k)}\right) \\
& +\left(\sum_{n} Q_{k j} S_{\text {trans }(k)}+\sum_{k} \sum_{j} Q_{k j} S_{\text {traus }(k))}\right) \\
& \Rightarrow \min
\end{aligned}
$$

$S_{\text {trans }}$ - the cost of shipping - consists of: $S_{\text {trans ik }}-$ the total cost of transportation service for a freight volume $Q_{i k}$ at the stage of shipping from supplier $i$ to terminal $k$, rub./year; $S_{\text {trans } k}-$ the total cost of terminal transportation (intra-terminal and inter-terminal), rub./ year; $S_{\text {trans } k j}$ - the total cost at the stage of dispersing a freight volume $Q_{k j}$ from terminal $k$ to consumers $j$, rub./year; $Q_{i k}$ - the amount of cargo coming from suppliers $i$ to terminal $k$, tons/day; $Q_{k j}$ the quantity of goods shipped (distributed) from terminal $k$ to consumers $j$, tons/day.

The total cost of transportation service $\left(S_{\text {sum }}^{(\beta ; \lambda ; \beta+\lambda)}{ }_{\alpha}\right)$ in $\alpha^{\varphi}$-phase $\left(\alpha_{1}=i k\right.$ - collection; $\alpha_{2}=k j-$ terminal transportation; $\alpha_{3}=k j-$ distribution) of freight flows by means of $\beta$-m or $\lambda$-m mode of transport ( $\beta$ - delivery by road; $\lambda$ - delivery by rail; $\beta+\lambda-$ multimodal delivery) are minimized according to the following parameters: location and planning of terminals; supplier $\left(\sum S_{i}\right)$, terminal $\left(\sum_{k} S_{k}\right)$, consumer $\left(\sum S_{i}\right)$, stages $m$ and $n(m-$ arrival of goods from a supplier to a terminal, $n$-departure of goods from a terminal to a customer) different for each transport combination.

Expanded form of the costs for construction and maintenance of a LCDC function:

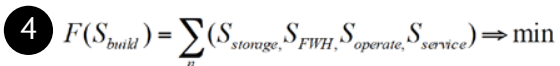

$S_{\text {build }}$ - the costs for construction and maintenance of a LCDC (a number of $n$ ), considering the investment in infrastructure and equipment, rub./year; $S_{\text {storage }}$ - the costs for the storage of freight at a terminal, rub./year; $S_{F W H}-$ the costs for freight warehouse handling (packaging, assembling etc.), rub./year; $S_{\text {operate }}$ - the costs for loading, unloading, and cross-docking operations rub./year;

$S_{\text {service }}$ - the costs connected with freight-forwarding and commercial information service, distribution, tracking and tracing and other logistics services, rub./year.

In addition to the financial indicators, the indicator of traffic efficiency of terminal goods is considered: $T_{\text {delivery }}-$ time of delivery using terminal technology, hour (Pokrovskaya 2012). The objective function $F$ takes the minimized indicators into account. However, there are maximized indicators as well. The form of the objective function $G$ for an optimum criterion - the maximum of the overall transportation service efficiency for $R_{\text {sum }}$ :

(5) $G=\sum R_{\text {sum }} \alpha^{(\beta, \lambda, \beta+\lambda)} \Rightarrow \max$

where $R_{\text {sum }}$ - the overall transportation service efficiency, rub./year.

The overall transportation service efficiency $\left(R_{\text {sum } \alpha}^{(\beta ; \lambda ; ; \beta+\lambda)}\right)$ in $\alpha$-phase $\left(\alpha_{1}=\right.$ ik - collection; $\alpha_{2}=\mathrm{kj}$ - terminal transportation, $\alpha_{3}=\mathrm{kj}$ - distribution) of freight flows by means of $\beta-\mathrm{m}$ or $\lambda$-m mode of transport ( $\beta$ - delivery by road, $\lambda-$ delivery by rail, $\beta+\lambda-$ multimodal delivery) in accordance with the objective function $G$ is maximized for each pa- rameter. The expanded form for the overall transportation service efficiency function is:

(6) $G\left(R_{\text {sum }}\right)=\left\lfloor R_{\log }, R_{C E}, R_{\text {soc }}, R_{\text {custamer }}, V_{\text {delivey }}\right\rfloor \Rightarrow \max$

where $R_{\log }$ - the efficiency of the logistics of freight forwarding, \%; $R_{C E}$ - the cost-effectiveness, \%; $R_{s o c}-$ the social efficiency of terminal technology, \%, $R_{\text {customer }}$ - customer satisfaction of transportation and logistics services using a terminal network point.

The efficiency of logistics/freight forwarding $R_{\log }$ refers to a timely delivery of goods to the assigned destination, the reliability of documentation, the information services and cargo safety. Social efficiency $R_{s o c}$ is determined by the social effect (new jobs, wage growth). Customer satisfaction of transportation and logistics services $R_{\text {customer }}$ involve a culture of service, customer convenience, the willingness of consumers to use the services offered and the range of services. In addition, the indicator for the terminal freight flow effectiveness and the speed of cargo delivery $V_{\text {delivery }}$, is included in the objective function in $\mathrm{km} / \mathrm{h}$. In order to analyze the influence of the terminal quantity and the location with regard to the total cost value of transportation service, one needs to determine the total costs for each of the possible options and evaluate the feasibility of each one. Maximizing the costs for the objective function allows identifying the best combination of the quantity and the location of the terminals in a region.

In the present study, we restrict the investigation area only to the objective function $F$, which determines the basic indicators influencing the final result significantly. Such metrics in a quantitative aspect are: the total cost of transportation service $S_{\text {sum }}(\beta ; \lambda ; \beta+\lambda){ }_{\alpha}$, rub./year; $S_{\text {trans }}$ - the costs for transportation, rub./year; $S_{\text {build }}$ - the construction expenditure (zero-base/on the base of operating infrastructure), and the maintenance of a certain amount of LCDCs, considering infrastructure and equipment investments, rub./year (Pokrovskaya 2012). Hence, the heuristic method, as a problem solving approach, was applied for developing the objective function under study. It implies an iterative procedure that con- 


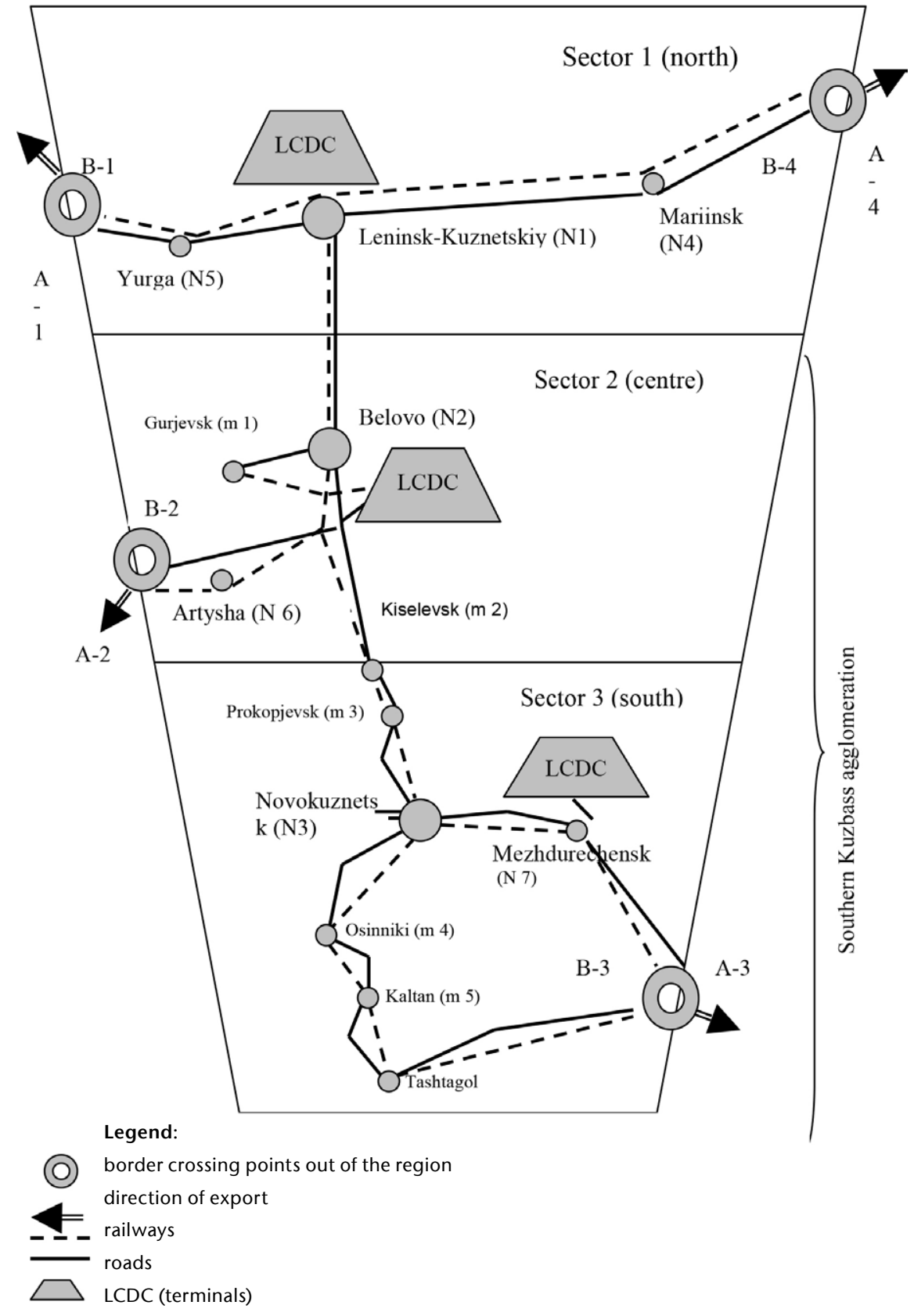

Fig. 1) The best option of Terminal networt

verges to an enumeration of possibilities with an additional accounting cycle of selecting a mode of transport (combination of transportation modes). Spatial/quantitative parameters of the terminal network are determined by varying the possible combinations of the LCDCs' number and location.

\section{Application Example of the Approach}

Here, a concrete example of the applicability of this objective function in real conditions is considered. We note that a large amount of calculation of outer areas. The railway transport, which has a well-developed network of roads, is the priority development in the region. This is due to the fact that coal mining companies have traditionally focused on the transport service by rail. The reasons are the large volume of freight traffic and the long distances of deliveries to consumers. However, there has recently been an outflow of goods transported over short distances on vehicles. Today, vehicles compete with the rail in the short and the relatively long distances to take the goods to the end consumer, due to the intensification of road constructions, a powerful increase in cargo traffic and the variety of rolling stock.

In this region, there are seven major industrial transport nodes (N1-N7) with terminals. The territory of the region is conventionally divided into three sectors: 1) the north; 2) the center; 3) the south. In the second sector of freight traffic, there are three generating points for goods (n1-3) and in the third sector six (N4-N9). The first sector is in the northern part of the region, which does not belong to the boundaries of the southern Kuzbass agglomeration. Therefore, the production and the distribution of this sector are taken into account, but not in detail. The export is carried out into four areas: A1 - European direction (north-west), A2 - southwest direction (the Altai, Kazakhstan), A3 - south-east direction (Khakassia), A4 - north-east direction (the Far East, the Krasnoyarsk Territory). Accordingly, there are four exits from the region $B 1-B 2$, the direction of $A 1-A 4: B 1-B o-$ lotnoje, B2 - Tiagun; B3 - Balyksa; B4 - Itat. These are the cities: B1 - Yurga, B2 - Artyshta, B3 - Mezhdurechensk, B4 - Mariinsk.

In order to streamline intra-regional economical ties and the export of coal products from the region to foreign destinations, we propose to establish three supporting terminals: LCDC1 - (Leninsk-Kuznetskiy), LCDC2 - (Belovo), LCDC3 - (Novokuznetsk), which is accepted as an initial hypothesis. LCDCs may be located in the geographical center of each sector equidistant from both industrial enterprises and exit points of the area. It is assumed that such a quantitative spatial arrangement of the terminal network in the region will provide a rational freight duction represents traffic flows of a powerful mass of bulk cargo to the 
Tab.1: The results of calculation of the terminal network options and the choice of the best option

\begin{tabular}{|c|c|c|c|c|c|c|}
\hline \multirow[t]{2}{*}{$\begin{array}{l}\text { Number and } \\
\text { dislocation } \\
\text { LCDC }\end{array}$} & \multicolumn{3}{|c|}{$\begin{array}{l}\text { Transportation costs to collect the goods from the territo- } \\
\text { ry of the region to the terminal/-s, } \\
S \text { trans. cost }\end{array}$} & \multicolumn{3}{|c|}{$\begin{array}{l}\text { Transportation cost for distribution of cargo from the } \\
\text { terminal/-s to the borders of the region, } \\
\text { S trans. distribution }\end{array}$} \\
\hline & $\begin{array}{c}\text { V } \\
\text { mln. rub./year }\end{array}$ & $\begin{array}{c}\text { RW } \\
\text { mln. rub./year }\end{array}$ & $\begin{array}{c}\text { V+RW } \\
\text { mln. rub./year }\end{array}$ & $\frac{\text { V }}{\text { mln. rub./year }}$ & $\begin{array}{c}\text { RW } \\
\text { mln. rub./year }\end{array}$ & $\begin{array}{c}\text { V+RW } \\
\text { mln. rub./year }\end{array}$ \\
\hline LCDC 7 & 11970,65 & 8240,36 & 8657,40 & 35695,35 & 11901,02 & 9603,45 \\
\hline LCDC 2,7 & 7938,00 & 7117,74 & 6902,28 & 31615,92 & 11260,62 & 9359,28 \\
\hline LCDC1,2,7 & 6102,45 & 6482,30 & 5914,30 & 28932,50 & 10539,95 & 9116,40 \\
\hline
\end{tabular}

$\mathrm{V}$ - vehicles, RW - railway transport, $\mathrm{V}+\mathrm{RW}$ - multi-transport delivery. In bold is the best option of the terminal network (BOTN). * It is calculated from the average value - $50 \%$ (using the existing infrastructure) ** It is calculated at the current value - $100 \%$ Table. 1 is diagrammed with a representation of the relation of the amount of expenses depending on number of relative positions of LCDC in the terminal network in the region.

movement in terms of reducing transport costs in each spatial sector and the whole region. The selected terminal network nodes are large cities with a developed industrial production, and they are located in the immediate vicinity of mining sites and the production of readymade products. The main transport links are going through the territory of the region under consideration. Figure 1 shows the best option for the terminal network chosen by the criterion of optimality of the objective function.

The calculation results are presented in Tab. 1 and Fig. 2.

\section{Conclusions}

Finding solutions for the proposed objective function is carried out using a heuristic method (iterative method of directed sorting options) with an additional investment settlement cycle - the choice of the form (a combination of forms) of transport. By varying the number of possible combinations and dislocations of LCDC, modes of transport for their service and the spatial and quantitative parameters of the terminal network are determined. Graphically, the minimum objective function falls on the best option of terminal networks that were mathematically derived. BOTN is represented by three nodes in the cities: Leninsk-Kuznetskiy (LCDC 1), Belovo (LCDC 2) and Mezhdurechensk (LCDC 7). Cost savings concerning shipping terminals confirm the need to create a network for the efficient organization of the transportation of goods in the region under consideration. Thus, this research characterizes and demonstrates the practical application of the objective function in the design of the terminal network. It proved that minimum total costs for transportation services exist through the verification of calculations using computer programs.

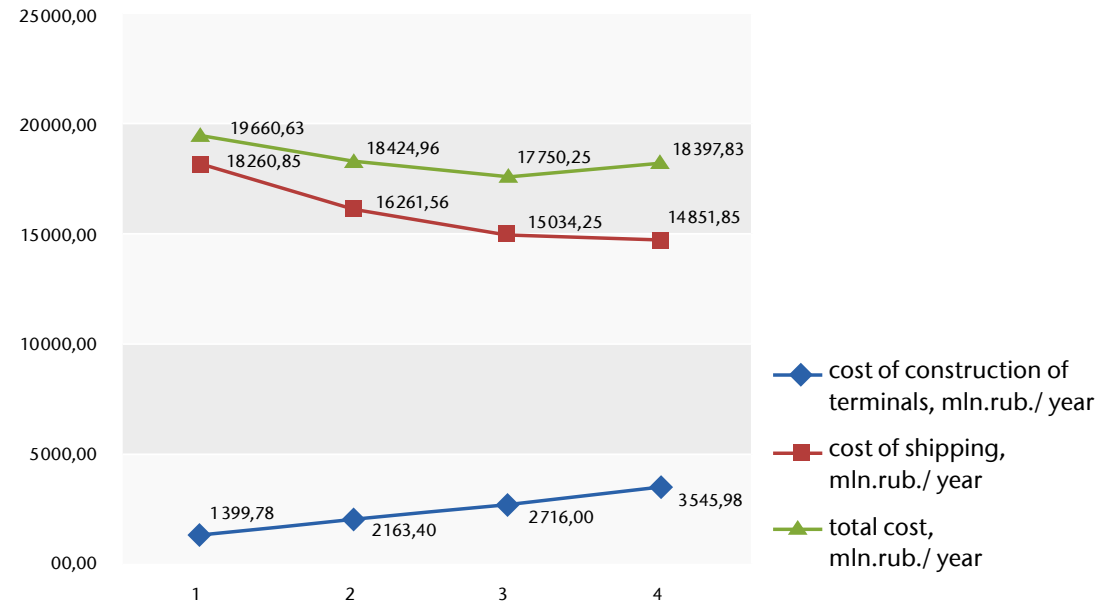




\section{Total cost of shipping for terminal circuit} (collection, distribution),

\section{$S$ trans. total}

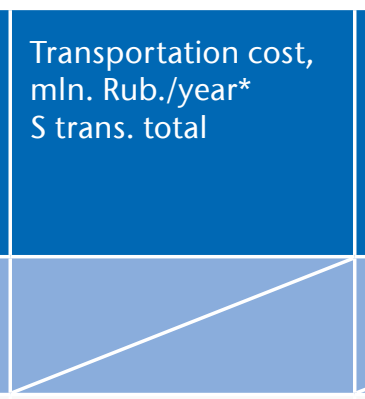

18260,85
Cost construction/

formation of LCDC,

mln. rub./year**

$S$ constr.
RW

mln. rub./year

20141,38

18382,14

17022,25

17399,55
V+RW

mln. rub./year

18260,85

16261,56

15034,25

15034,25

14851,85
Total cost,

mln. Rub./year

S total
1399,78

19660,63

18424,96

17750,25

18397,83

\section{REFERENCES}

Pokrovskaya OD (2012) Формирование терминальной сети региона для организации перевозок грузов (Formation of a regional terminal network for the transportation of goods). TransLit, Moskva. ISBN: 978-5-94976452-7

Pokrovskaya OD, Samuylov VM, Nevolina AD (2013) Инфраструктура международных транспортных коридоров (Infrastructure of the international transport corridors). Иннов трансп научно-публ изд I Innotrans Sci Nonfict Ed 3(9):33-37

Samuylov VM, Galkin AG, Koshkarov VE, Kiselev SA (2012) Развитие международного автотранспортного коридора на территории Свердловской области в системе модернизациитранспортной инфраструктуры Урала (The development of the international transport corridor in the territory of the Sverdlovsk region in the system of modernization of the transport infrastructure of the Urals). Иннов трансп научно-публ изд | Innotrans Sci Nonfict Ed 2(3):23-33

Ungvári L, Gashkova LV, Samuylov VM (2014) Модуль «Встроенное образование» на базе НОЦ «Транс- портная логистика» ("Integrated Education" Module based on REC "Transport Logistics"). Иннов трансп научнопубл изд | Innotrans Sci Nonfict Ed 12(2):75-78

\section{AUTHORS}

Valery M. Samuylov, DSc, Professor Lyudmila V. Gashkova, Associate Professor Ural State University of Railway Transport Ekaterinburg, Russian Federation

Oksana D. Pokrovskaya, PhD, Associate Professor Siberian State University of Railway Transport Novosibirsk, Russian Federation

Prof. Dr.-Ing. Herbert Sonntag

Technische Hochschule Wildau I

Technical University of Applied Sciences

Forschungsgruppe Verkehrslogistik

Wildau, Germany

E-Mail for correspondence:

herbert.sonntag@th-wildau.de 